OPEN ACCESS

Edited by:

Manuel Perea

University of Valencia, Spain

Reviewed by:

Claudio Mulatti,

University of Trento, Italy

Anthony James Krafnick,

Dominican University, United States

${ }^{*}$ Correspondence:

Yongsheng Wang

wangyongsheng@mail.tjnu.edu.cn

Xuejun Bai

bxuejun@126.com

Specialty section:

This article was submitted to

Language Sciences,

a section of the journal

Frontiers in Psychology

Received: 04 September 2020

Accepted: 06 January 2021

Published: 28 January 2021

Citation:

Chen $M$, Wang Y, Zhao B, Li X and Bai $X$ (2021) The Trade-Off

Between Format Familiarity and Word-Segmentation Facilitation in Chinese Reading.

Front. Psychol. 12:602931. doi: 10.3389/fpsyg.2021.602931

\section{The Trade-Off Between Format Familiarity and Word-Segmentation Facilitation in Chinese Reading}

\author{
Mingjing Chen, Yongsheng Wang*, Bingjie Zhao, Xin Li and Xuejun Bai* \\ Key Research Base of Humanities and Social Sciences, Institute of Psychology and Behavior, Tianjin Normal University, \\ Tianjin, China
}

In alphabetic writing systems (such as English), the spaces between words mark the word boundaries, and the basic unit of reading is distinguished during visuallevel processing. The visual-level information of word boundaries facilitates reading. Chinese is an ideographic language whose text contains no intrinsic inter-word spaces as the marker of word boundaries. Previous studies have shown that the basic processing unit of Chinese reading is also a word. However, findings remain inconsistent regarding whether inserting spaces between words in Chinese text promotes reading performance. Researchers have proposed that there may be a trade-off between format familiarity and the facilitation effect of inter-word spaces. In order to verify this, this study manipulated the format familiarity via reversing the Chinese reading direction from right to left to investigate this issue in Experiment 1 and Experiment 2. The purpose of Experiment 1 was to examine whether inter-word spaces facilitated Chinese reading in an unfamiliar format. Experiment 1 was conducted that 40 native Chinese undergraduates read Chinese sentences from right to left on four format conditions. The results showed faster reading speed and shorter total reading time for the inter-word spaced format. Based on this finding, Experiment 2 examined whether the facilitation effect of inter-word spaces would reduce or disappear after improving the format familiarity; this experiment was conducted that 40 native Chinese undergraduates who did not participate in Experiment 1 read Chinese sentences from right to left on four format conditions after ten-day reading training. There was no significant difference between the total reading time and reading speed in the inter-word spaced format and unspaced format, which suggests that the facilitation effect of inter-word spaces in Chinese reading changed smaller. The combined results of the two experiments suggest that there is indeed a trade-off between format familiarity and the facilitation of word segmentation, which supports the assumption of previous studies.

Keywords: trade-off, format familiarity, word segmentation, Chinese reading, eye movements 


\section{INTRODUCTION}

As the saying goes, "Read wide, and you will wisely write." In other words, reading is the basic way for humans to acquire information, as well as an effective way to inherit human knowledge and civilization. Different civilizations have produced different languages with different characteristics. For example, Chinese is an ideographic language that differs from an alphabetic language like English, whose texts contain intrinsic inter-word spaces as word boundary markers. The basic independent unit of reading processing whether in Chinese or English is the word (Rayner, 1998, 2009; Rayner et al., 1998; Reichle et al., 1999; Inhoff et al., 2000; Yan et al., 2006; Li et al., 2009; Perea and Acha, 2009). The primary task for readers of Chinese is to segment words from Chinese texts which do not contain inter-word spaces as an indicator of word segmentation. The characteristic of no inter-word spaces has been the subject of many studies focusing on the mechanism of word segmentation in Chinese reading (Rayner, 1998; Bai et al., 2008; Bassetti, 2009; Li et al., 2009, 2014; Cui et al., 2014; Zang et al., 2016; Ma, 2017; Liu and Lu, 2018; Ma and Zhuang, 2018; Zhou et al., 2020). Moreover, the reading direction is one of the significant characteristics among languages. In some languages, such as Hebrew and Arabic, text by default is read from right to left (Deutsch and Rayner, 1999). The default direction of ancient Chinese texts was also from right to left and from top to bottom. However, the direction of modern Chinese texts has changed to a left to right direction, which is a familiar reading format for native Chinese readers. This poses the following questions: when reading texts with an unfamiliar format which differs from the default format (for example, Arabic readers whose default format is reading from right to left in arabic texts read Chinese texts from left to right in unfamiliar format), how do readers understand and process the information given in the unfamiliar format? Does reading performance change under unfamiliar format? Are there any differences between reading processing in the unfamiliar format and the familiar format? These questions need to be explored in psychology of reading.

It is a subject of debate whether inter-word spaces as indicators of word segmentation could promote Chinese reading. Many studies have supported inter-word spaces being explicit indicators that promote word recognition and reading processing (Yan et al., 2010; Li et al., 2011a; Zang et al., 2013; Bai et al., 2015). However, some researchers did not find evidence of inter-word spaces facilitating reading; a representative study is that by Bai et al. (2008). In this study, the segmentation was manipulated to present Chinese sentences in different formats (unspaced format, inter-word spaced format, inter-character spaced format, non-word spaced format) to native Chinese readers in natural reading. However, the results did not completely support the research hypothesis: there was no facilitation effect of interword spaces. To explain this finding, it was proposed that there may be a trade-off between format familiarity and wordsegmentation facilitation in Chinese reading. This means that inter-word spaces do indeed facilitate Chinese reading; however, the format unfamiliarity of inserting spaces into texts offsets the facilitation of word segmentation. To verify this proposal, the following studies found that inter-word spaces facilitated Chinese reading for foreign students and children with dyslexia (Bai et al., 2009; Wang et al., 2010; Shen et al., 2012; Zang et al., 2013). What these participants had in common was a low level of proficiency in Chinese reading; in addition, they were unfamiliar with the format of unspaced Chinese texts, which was caused by their insufficient reading experience. Therefore, inter-word spaces facilitated reading in this unfamiliar format. However, the studies using Chinese native readers as participants did not find that inter-word spaces promoted the reading process in the familiar format (Shen et al., 2010; Yan et al., 2012). In summary, the format familiarity of Chinese text was the distinguishing factor between the studies finding that inter-word spaces facilitated reading and those that found no evidence of facilitation.

Based on previous findings, this study manipulated word segmentation and format familiarity to investigate whether there is a trade-off between format familiarity and word-segmentation facilitation in Chinese reading. In Experiment 1, the Chinese sentences were presented in four segmented formats (unspaced format, inter-character spaced format, inter-word spaced format, non-word spaced format). Chinese readers were required to read from right to left, which was an unfamiliar format for them. In Experiment 2, the reading training (reading the Chinese texts from right to left) was manipulated to improve participants' familiarity with the format. Following this, the same Chinese sentences were presented in the same four segmented formats and the Chinese readers were required to read from right to left after having improved their familiarity with the format. Based on the assumption that there is a trade-off between format familiarity and word-segmentation facilitation in Chinese reading, if the results of Experiment 1 showed that inserting spaces between words did indeed facilitate the reading process, this would prove that inter-word spaces did facilitate reading in the unfamiliar format. On the other hand, if inserting spaces between words did not promote Chinese reading, it would imply that inter-word spaces did not facilitate reading in the unfamiliar format.

After obtaining the results in Experiment 1, the study turned to Experiment 2. The unfamiliar format was changed to a familiar format via reading training in Chinese reverse texts. If the facilitation of word segmentation reduced or disappeared under this condition, it would verify that the facilitation was offset or partly offset by the format familiarity. On the other hand, if nothing changed with the facilitation of word segmentation, then it would imply that the format familiarity did not affect inter-word spaces facilitating Chinese reading by giving wordsegmentation indications.

\section{EXPERIMENT 1}

The purpose of Experiment 1 was to determine whether interword spaces facilitate Chinese reading in an unfamiliar format without relevant reading experience.

\section{Method \\ Participants}

The participants in Experiment 1 were 40 undergraduate students (mean ages $20.78 \pm 1.21$ years). There were 28 females and 
12 males; their mother tongue was Chinese; they had normal or corrected vision; and they were right-handed dominant. Each participant signed a project agreement form before the experiment commenced. Based on the Declaration of Helsinki (BMJ 1991; 302: 1194), Tianjin Normal University's Medical Ethical Committee approved the experiment.

\section{Experimental Design and Materials}

The experimental design was a single-factor (word segmentation) within-subjects design which contained four conditions: (1) Unspaced format: Chinese default format with no spaces in sentences; (2) Inter-character spaced format: spaces between adjacent characters in sentences; (3) Inter-word spaced format: spaces between words in sentences; (4) Non-word spaced format: spaces were randomly inserted between sentences to turn adjacent words into non-words. Examples of sentences in the four conditions are shown in Table 1.

A total of 60 Chinese sentences were constructed, which all ranged between 15 and 17 characters in length $(\mathrm{M}=15.8$ characters, $\mathrm{SD}=0.80$ characters). The experimental sentences were rated on a seven-point scale for their naturalness by 30 participants who did not take part in the eye-tracking experiment. The mean naturalness score was 6.69 (where a score of 7 was very natural) and the consistency of the word segmentation in sentences was $91 \%$ by 12 participants who did not take part in the eye-tracking experiment. Experiment 1 constructed four files, each of which had 60 sentences. The 60 sentences were allocated to the four conditions, which were rotated in the form of a Latin square and contained 15 sentences. The blocked format was the presented format of sentences in each condition, which had a random order. Each file contained 12 practical sentences which was allocated to four conditions, each of which contained three sentences. The 12 practical sentences were presented to be read first in each file. Participants needed to answer yes/no after each of 22 sentences, after which followed a comprehension question where the number of yes and no responses was equal. Each participant read 72 sentences in total.

\section{Apparatus}

The experiment recorded right-eye movements using EyeLink 1000 (SR Research, Canada); the sampling rate was $1,000 \mathrm{~Hz}$, while the accuracy rate was a $0.5^{\circ}$ visual angle. We adjusted the resolution of the stimulus presented on a 19 -inch Dell monitor to $1,024 \times 768$. In the experiment, participants maintained a distance of $70 \mathrm{~cm}$ from the screen. The characters had a size of

TABLE 1 | Example Chinese stimuli from the four conditions used in the experiment.

\begin{tabular}{ll}
\hline Word segmentation & Sentence example \\
\hline Unspaced format & 。利有康健体身对动运育体加参常经 \\
Inter-character spaced format & 。利有康健 体身 对动运育体加参常经 \\
Inter-word spaced format & 。利有 康健 体身 对动运 育体 加参常经 \\
Non-word spaced format & 。利 有康 健体 身对动运育 体加参常经
\end{tabular}

The English translation for the sentence is "Regular participation in sports is good for health." “经常参加体育运动对身体健康有利” is the Chinese sentence in the normal format.
$25 \times 25$ pixels and the visual angle was $0.80^{\circ}$, and they were presented in sentences in the Song font.

\section{Procedure}

The participants were told to read sentences from right to left in different conditions before the experiment. Participants needed to understand the meaning of sentences as quickly as possible and press the space bar to read the next sentence. In some sentences a comprehension question followed, which participants had to then answer as correctly as possible. Chin rests were used to ensure that participants' heads remained in a resting position to compensate for head movement. A calibration was completed before the experiment to calculate the position of the fixed point. Participants started the test after successful calibration. If necessary, the eye location would be recalibrated during the experiment. The experiment lasted about $20 \mathrm{~min}$. The participants' responses to the comprehension questions achieved a correctness rate of $91.0 \%$, which indicated that the sentences had been read and understood.

\section{Data Preparation and Analysis}

According to the following criteria (Rayner et al., 2006; Bai et al., 2008; Rayner, 2009; Liu et al., 2017; Wang et al., 2018), the analysis of fixation durations excluded data shorter than $80 \mathrm{~ms}$ and longer than $800 \mathrm{~ms}$. The data were excluded if: (1) participants pressed the key incorrectly during the experiment, which resulted in an interruption; (2) data were lost due to accidental factors (such as head movement); (3) there were fewer than four gazes; (4) the data were outside three standard deviations. After excluding invalid data ( $2.8 \%$ of the total data), data analysis was conducted.

The experiment computed eye-movement measures of target words as follows: (1) Mean fixation duration (average fixation duration in all fixated points in the sentence); (2) Mean saccadic length (average length of all saccades from the current fixated point to the next one in the sentence); (3) Number of fixations (number of all fixations in the sentence); (4) Total fixation duration (sum of the fixation duration in all fixation points in the sentence); (5) Reading speed (average number of reading words per second in the sentences); (6) Forward saccadic length (saccadic length reading from right to left). The units of the time index (mean fixation duration; total fixation duration) were milliseconds; the units of the mean saccadic length and forward saccadic length were characters; while characters per second were the units of reading speed. SPSS 20 for Windows (SPSS Inc., Chicago, IL, United States) was used to process statistical data. A repeated-measures analysis of variance, including subject analysis $\left(\mathrm{F}_{1}\right)$ and item analysis $\left(F_{2}\right)$, was conducted (Shen et al., 2010; Bai et al., 2012a, 2015; Zang et al., 2013).

\section{Results}

The results of the global analysis are shown in Tables $\mathbf{2 A}, \mathbf{2 B}, \mathbf{3}$.

The results showed a significant word-segmentation effect in the mean fixation duration: $F_{1}(3,117)=61.82, p<0.001$, $\eta^{2}=0.61 ; F_{2}(3,177)=59.46, p<0.001, \eta^{2}=0.50$. Furthermore, the results of the post hoc test showed no significant difference 
TABLE 2A | Global eye movement measure under four conditions.

\begin{tabular}{|c|c|c|c|c|}
\hline & Unspaced format & Inter-character spaced format & Inter-word spaced format & Non-word spaced format \\
\hline Mean fixation duration & $262(43)$ & $236(34)$ & $241(39)$ & $242(36)$ \\
\hline Mean saccadic length & $2.62(1.03)$ & $4.10(1.38)$ & $3.75(1.32)$ & $3.56(1.25)$ \\
\hline Number of fixations & $14.4(5.55)$ & $15.68(5.60)$ & $14.11(5.14)$ & $14.86(5.31)$ \\
\hline Total fixation duration & 4385 (1817) & $4412(1732)$ & 3993 (1583) & 4312 (1749) \\
\hline Reading speed & $4.31(2.11)$ & $4.17(1.85)$ & $4.60(2.04)$ & $4.33(2.01)$ \\
\hline Forward saccadic length & $2.16(1.42)$ & $3.19(1.98)$ & $2.97(1.85)$ & $2.89(1.85)$ \\
\hline
\end{tabular}

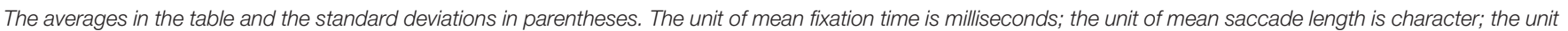
of total time is milliseconds; the unit of reading speed is character per second; the unit of forward saccade length is character.

TABLE 2B | The 95\% confidence intervals of global eye movement measure under four conditions.

\begin{tabular}{|c|c|c|c|c|c|c|c|c|c|}
\hline & & \multicolumn{2}{|c|}{ Unspaced format } & \multicolumn{2}{|c|}{ Inter-character spaced format } & \multicolumn{2}{|c|}{ Inter-word spaced format } & \multicolumn{2}{|c|}{ Non-word spaced format } \\
\hline & & Lower & Upper & Lower & Upper & Lower & Upper & Lower & Upper \\
\hline \multirow[t]{2}{*}{ Mean fixation duration } & $F_{1}$ & 252 & 270 & 229 & 242 & 232 & 248 & 234 & 249 \\
\hline & $F_{2}$ & 259 & 266 & 234 & 239 & 238 & 244 & 239 & 245 \\
\hline \multirow[t]{2}{*}{ Mean saccadic length } & $F_{1}$ & 2.38 & 2.89 & 3.84 & 4.63 & 3.46 & 4.14 & 3.30 & 3.97 \\
\hline & $F_{2}$ & 2.54 & 2.71 & 4.00 & 4.25 & 3.64 & 3.88 & 3.47 & 3.67 \\
\hline \multirow[t]{2}{*}{ Number of fixations } & $F_{1}$ & 13.01 & 15.57 & 14.24 & 16.79 & 12.87 & 14.97 & 13.54 & 15.82 \\
\hline & $F_{2}$ & 13.67 & 15.17 & 14.75 & 16.56 & 13.36 & 14.69 & 14.23 & 15.50 \\
\hline \multirow[t]{2}{*}{ Total fixation duration } & $F_{1}$ & 3894 & 4745 & 3939 & 4766 & 3583 & 4287 & 3583 & 4287 \\
\hline & $F_{2}$ & 4110 & 4621 & 4112 & 4686 & 3751 & 4183 & 4091 & 4532 \\
\hline \multirow[t]{2}{*}{ Reading speed } & $F_{1}$ & 3.84 & 4.91 & 3.77 & 4.68 & 4.17 & 5.13 & 3.88 & 4.87 \\
\hline & $F_{2}$ & 4.07 & 4.61 & 3.92 & 4.49 & 4.36 & 4.90 & 4.09 & 4.62 \\
\hline \multirow[t]{2}{*}{ Forward saccadic length } & $F_{1}$ & 2.05 & 2.57 & 3.06 & 3.92 & 2.83 & 3.51 & 2.75 & 3.44 \\
\hline & $F_{2}$ & 2.13 & 2.24 & 3.16 & 3.35 & 2.93 & 3.10 & 2.86 & 3.03 \\
\hline
\end{tabular}

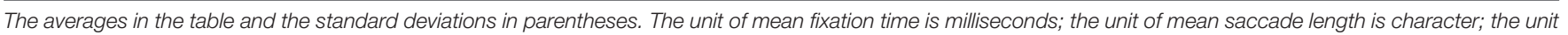

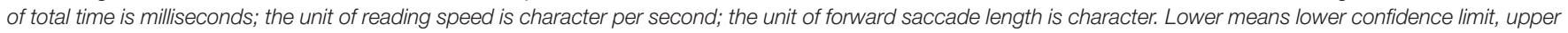
means upper confidence limit. $F_{1}$ means the subject analysis, $F_{2}$ means the item analysis.

TABLE 3 | F values, degrees of freedom, $p$ values, $\eta^{2}$ values, and post hoc comparisons for each index.

\begin{tabular}{|c|c|c|c|c|c|c|}
\hline Index & & $\boldsymbol{F}$ & $d f$ & $p$ & $\eta^{2}$ & Post hoc comparisons, $p<0.05$ \\
\hline \multirow[t]{2}{*}{ Mean fixation duration } & $F_{1}$ & 61.82 & 3,117 & $<0.001$ & 0.61 & Condition 1 > Condition 2, Condition 1 > Condition 3 ; \\
\hline & $F_{2}$ & 59.46 & 3,177 & $<0.001$ & 0.50 & Condition 1 > Condition 4; Condition 4 > Condition 2 \\
\hline \multirow[t]{2}{*}{ Mean saccadic length } & $F_{1}$ & 188.44 & 3,117 & $<0.001$ & 0.77 & Condition $2>$ Condition 1, Condition 2 > Condition 3; Condition $2>$ Condition 4; \\
\hline & $F_{2}$ & 149.32 & 3,177 & $<0.001$ & 0.68 & Condition 3 > Condition 1; Condition 3 > Condition 4; Condition $4>$ Condition 1 ; \\
\hline \multirow[t]{2}{*}{ Number of fixations } & $F_{1}$ & 11.61 & 3,117 & $<0.001$ & 0.23 & Condition 2 > Condition 1, Condition 2 > Condition 3 \\
\hline & $F_{2}$ & 3.90 & 3,177 & 0.010 & 0.062 & Condition 2 > Condition 4; Condition 4 > Condition 3; \\
\hline \multirow[t]{2}{*}{ Total fixation duration } & $F_{1}$ & 10.88 & 3,117 & $<0.001$ & 0.22 & Condition $3<$ Condition 1, Condition $3<$ Condition 2, Condition $3<$ Condition 4; \\
\hline & $F_{2}$ & 2.82 & 3,177 & 0.04 & 0.05 & \\
\hline \multirow[t]{2}{*}{ Reading speed } & $F_{1}$ & 10.84 & 3,117 & $<0.001$ & 0.22 & Condition $3>$ Condition 1, Condition $3>$ Condition 2, Condition $3>$ Condition 4; \\
\hline & $F_{2}$ & 1.85 & 3,177 & 0.14 & & \\
\hline \multirow[t]{2}{*}{ Forward saccadic length } & $F_{1}$ & 128.84 & 3,117 & $<0.001$ & 0.77 & Condition 2 > Condition 1, Condition 2 > Condition 3 , \\
\hline & $F_{2}$ & 127.65 & 3,177 & $<0.001$ & 0.68 & Condition 2 > Condition 4; Condition 3 > Condition 1; \\
\hline
\end{tabular}

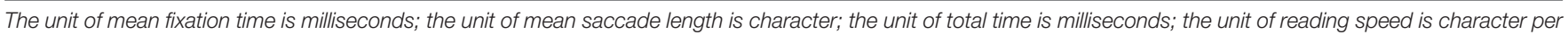

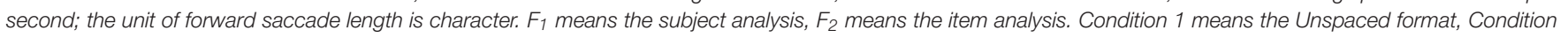
2 means the inter-character spaced format, Condition 3 means the inter-word spaced format, Condition 4 means the non-word spaced format.

between the inter-word spaced condition and the non-word spaced condition, $p>0.05$. The difference between intercharacter spaced condition and inter-word spaced condition was also not significant, $p>0.05$. There were significant differences between each of the other two conditions, $p_{s}<0.05$.
The mean fixation duration of the unspaced format was the longest, $p_{s}<0.001$. The mean fixation duration of the intercharacter spaced format was the shortest, $p_{s}<0.05$. This meant that participants took a shorter duration to process words and understand the Chinese sentences. Inserting spaces into 
characters in Chinese sentences could reduce the difficulty of Chinese reading.

In Chinese, the saccade length, which reflects the language information in the unit space, is generally only two to three Chinese characters (Inhoff and Liu, 1998; Yan and Bai, 2007; Yan et al., 2013). A longer saccade length indicates that the participants obtained relatively more information during the saccade fixation (Irwin, 1998; Yan and Bai, 2000; Yan et al., 2013). There was a significant word-segmentation effect in the mean saccadic length: $F_{1}(3,117)=188.44, p<0.001, \eta^{2}=0.83$; $F_{2}(3,177)=149.32, p<0.001, \eta^{2}=0.72$. The results of the post hoc test showed that there was a significant difference between each of the two conditions, $p s<0.01$. The mean saccadic length in the inter-character spaced format was the longest, $p s<0.001$. The mean saccadic length in the interword spaced format was longer than that in the unspaced format which was the shortest, $p<0.001$. The main effect of word segmentation was significant in the forward saccadic length format, $F_{1}(3,117)=128.84, p<0.001, \eta^{2}=0.77 ; F_{2}$ $(3,177)=127.65, p<0.001, \eta^{2}=0.68$. Furthermore, the results of the post hoc test showed that forward saccadic length in the intercharacter spaced format was the longest, significantly longer than in the other conditions, $p s<0.001$. Forward saccadic length in the inter-word spaced format was significantly longer than that of the unspaced format, $p<0.001$. The forward saccadic length in the non-word spaced format was significantly longer than in the unspaced format, $p<0.05$, which was marginally shorter than that in the inter-word spaced format, $p=0.068$.

The number of fixations refers to the number of all fixation points, which could reflect the cognitive load of the reading material (Yan et al., 2013). The more difficult and complex the reading materials are, the higher the number of fixations (Henderson and Ferreira, 1990; Yan et al., 2013). The higher the reading level, the lower the number of fixations for the same reading material (Rayner et al., 2011). We found that there was a significant word-segmentation effect in the number of fixations: $F_{1}(3,117)=11.61, p<0.001, \eta^{2}=0.23 ; F_{2}(3,177)=3.90$, $p=0.010, \eta^{2}=0.062$. The results of the post hoc test showed that the number of fixations in the inter-character spaced format was the highest, $p_{s}<0.05$. The number of fixations in the interword spaced format was less than that of the non-word spaced format, $p<0.05$. The difference between other conditions was not significant, $p_{s}>0.05$. The number of fixations in the interword spaced condition was significantly less than that under non-word spaced condition, which may be due to non-word spaces interfering with word segmentation and increasing the difficulty of reading.

The total reading time is sensitive to slower and longer cognitive processing, which can reflect the processing difficulty of reading sentences (Rayner et al., 2011; Yan et al., 2013). In the results, the main effect of word segmentation was significant, $F_{1}(3,117)=10.88, p<0.001, \eta^{2}=0.22 ; F_{2}(3,177)=2.82, p<0.05$, $\eta^{2}=0.05$ The results of the post hoc test showed that the total fixation duration in the inter-word spaced format was the shortest of the four conditions, $p_{s}<0.01$. The difference between each of the other conditions was not significant, $p_{s}>0.05$. This implies that inter-word spaces as word-segmentation clues could shorten the reading time and reduce the difficulty of Chinese texts. The reading speed represented the Chinese characters read per second. A faster reading speed means faster processing to understand the words and sentences and a lower difficulty with word recognition and reading comprehension. The results showed that the main effect of word segmentation on reading speed was significant, $F_{1}(3,117)=10.84, p<0.001$, $\eta^{2}=0.22 ; F_{2}(3,177)=1.849, p=0.140$. Furthermore, the results of the post hoc test showed that the reading speed in the inter-word spaced format was significantly faster than in the other conditions, $p s<0.05$. The difference between each other conditions was not significant, $p_{s}>0.05$. The reading speed in the inter-character spaced format was slower than that in the unspaced format, but the difference between them was not significant, $p_{s}>0.05$. The reading speed on intercharacter spaced format was slowest, which was not significant with that on the unspaced format and non-word spaced format, $p_{s}>0.05$. This showed that the inter-word spaces as word boundaries provided visual clues that facilitated Chinese reading and improved the reading speed, which is a finding consistent with previous results (Bai et al., 2009, 2015, 2014; Shen et al., 2010, 2012; Yan et al., 2010; Li and Pollatsek, 2011; Li et al., 2011b; Zang et al., 2013). In sum, the results in experiment 1 supported the research hypothesis.

\section{Discussion}

The purpose of Experiment 1 was to determine whether interword spaces could facilitate Chinese reading in an unfamiliar format without relevant reading experience. We used four wordsegmentation conditions to compare the eye movements of participants reading Chinese sentences from right to left in an unfamiliar format.

The previous results did not show the effect of interword spaces facilitating Chinese reading (Bai et al., 2008). The assumption proposed was that there was a trade-off between format unfamiliarity and facilitation effect of inter-word spaces in Chinese reading. The results showed that inserting spaces into words as indicators of word segmentation facilitated Chinese reading in the unfamiliar format, which supports the assumption. The logic behind this finding is that if there is a trade-off between format unfamiliarity and the facilitation of inter-word spaces, then the facilitation effect of inter-word spaces is offset by the format unfamiliarity of inserting spaces between words. However, the texts in the unspaced format had the format familiarity of the Chinese default format. There was no difference in the total reading time and reading speed between the inter-word spaced format and unspaced format. Therefore, if readers were both unfamiliar with the unspaced format and inter-word spaced format, the facilitation effect of inter-word spaces would not be offset by the unfamiliarity of the format. The results showing the total reading time was shorter and the reading speed was faster in the inter-word spaced format compared to the unspaced format indeed supported the assumption that there was a trade-off between format unfamiliarity and the facilitation effect of interword spaces in Chinese reading. In addition, the total reading time in the inter-word spaced format was shorter than that in the inter-character spaced format and non-word spaced format, 
which had the longest reading time. This may be due to the basic unit of information processing Chinese being a word rather than a character.

According to the results in Experiment 1, the readers' familiarity with the format affected the facilitation effect of inter-word spaces; the inter-word spaces significantly facilitated Chinese reading where readers lacked reading experience of reverse text from right to left. We can therefore assume that with increased reading experience of Chinese reversed texts, the facilitation effect of inter-word spaces would gradually decrease or even disappear. This problem will be further verified in Experiment 2.

\section{EXPERIMENT 2}

Experiment 1 showed that the inter-word spaces facilitated Chinese reading in an unfamiliar format in participants without relevant reading experience. Based on this finding, Experiment 2 focused on whether the facilitation effect of inter-word spaces would change with increased reading experience from right to left following reading training. Therefore, the combined results of Experiment 1 and 2 will demonstrate whether there is a tradeoff between format unfamiliarity and the facilitation effect of inter-word spaces in Chinese reading.

\section{Method \\ Participants}

The participants in Experiment 2 were 40 undergraduate students who did not participate in Experiment 1 (mean ages $20.50 \pm 1.63$ years). There were 31 females and 9 males; their mother tongue was Chinese; they had normal or corrected vision; and they were right-handed dominant. Each participant signed a project agreement form before the experiment commenced. Based on the Declaration of Helsinki (BMJ 1991; 302: 1194), Tianjin Normal University's Medical Ethical Committee approved the experiment.

\section{Experimental Design and Materials}

The experimental design was a single-factor (word segmentation) within-subjects design which contained four condition, same as that in experiment 1. Examples of sentences in the four conditions are shown in Table 1. The materials used for the eye-movement tests were the same as in Experiment 1.

The materials in the reading training were 60 Chinese essays (average number of words $M=936$ ) chosen from Chinese highschool textbooks, which were reversed from left-right format to right-left format through reversing software (see the Appendix for examples of reading materials).

\section{Apparatus}

The apparatus was same as that in Experiment 1.

\section{Procedure}

The procedure involved stages of reading training and eye movement. Firstly, participants entered the laboratory and were made familiar with the environment every day. Then the participants sat in their own seats where the experiment book was presented, which contained essays that the participants needed to read every day. The participants then read essays. Before the reading commenced, the researcher would give the following instruction: "Below you will read some articles. The sentences in the article will be presented from right to left. Please read carefully word by word and understand the article as much as possible. Seven reading comprehension questions will appear after each article. You are required to select the most appropriate answer based on the article and fill in the answer." The participants began to read an article after understanding the instruction and then answered seven questions, before moving on to the next question.

The reading training lasted for $30 \mathrm{~min}$ every day for ten days. After 10 days of reading training, eye-movement testing began, followed the same procedure as Experiment 1. The participants' responses to the comprehension questions in the eye-movement stage achieved a correctness rate $93.0 \%$, which indicated that the sentences had been read and understood the sentences seriously.

\section{Data Preparation and Analysis}

According to the following criteria which were same as that in Experiment 1 (Rayner et al., 2006; Bai et al., 2008; Rayner, 2009; Li et al., 2017; Liang et al., 2017; Wang et al., 2018), analysis data was selected. After excluding invalid data (1.65\% of the total data), data analysis was conducted.

The experiment computed eye-movement measures of target words which were same as that in the experiment 1 . The same method in experiment 1 was used to process the statistical data. A repeated-measures analysis of variance, including subject analysis $\left(\mathrm{F}_{1}\right)$ and item analysis $\left(\mathrm{F}_{2}\right)$, was conducted (Shen et al., 2010; Bai et al., 2012a,b, 2015; Yu et al., 2018).

\section{Results}

The results of the global analysis are shown in Tables 4A, 4B, 5 .

The results of time indicators including mean fixation time, number of fixations, total time and reading speed, and space indicators including mean saccadic length and forward saccadic length are presented as follows.

Firstly, in the time metric results, there was a significant word-segmentation effect in the mean fixation duration: $F_{1}(3,117)=76.6, p<0.001, \eta^{2}=0.66 ; F_{2}(3,177)=25.70$, $p<0.001, \eta^{2}=0.30$. The post-test results showed no significant difference between the inter-word spaced condition and intercharacter spaced condition, $p>0.05$. There were significant differences between each of the other two conditions, $p_{s}<0.05$. The mean fixation duration of the unspaced condition was the longest, $p_{s}<0.001$, which implies that the lack of word spaces caused interference in Chinese reading. It is surprising that the facilitation effect of inter-word spaces did not appear in the total time and reading speed. The main effect of word segmentation was significant on total time, $F_{1}(3,117)=18.01$, $p<0.001, \eta^{2}=0.42 ; F_{2}(3,177)=6.05, p=0.001, \eta^{2}=0.09$. The post hoc test showed that there was not a significant difference between the total time in the unspaced format and the interword spaced format, $p_{s}>0.05$. This result was consistent with the assumption that the facilitation effect of inter-word spaces changed smaller. Furthermore, there was not a significant 
TABLE 4A | Global eye movement measure under four conditions.

\begin{tabular}{|c|c|c|c|c|}
\hline & Unspaced format & Inter-character spaced format & Inter-word spaced format & Non-word spaced format \\
\hline Mean fixation duration & $260(37)$ & 237 (34) & $236(37)$ & $243(37)$ \\
\hline Mean saccadic length & 2.07 (0.73) & $3.45(1.15)$ & $2.80(0.95)$ & $2.73(0.95)$ \\
\hline Number of fixations & $10.60(3.52)$ & $12.17(3.96)$ & $11.16(3.66)$ & $11.77(4.07)$ \\
\hline Total fixation duration & $3116(1087)$ & 3313 (1103) & $3043(1034)$ & $3266(1122)$ \\
\hline Reading speed & $5.55(1.98)$ & $5.20(1.78)$ & 5.65 (1.87) & $5.25(1.88)$ \\
\hline Forward saccadic length & $2.21(1.17)$ & $3.34(1.74)$ & $2.98(1.50)$ & $2.88(1.41)$ \\
\hline
\end{tabular}

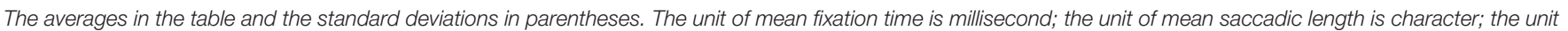
of total time is millisecond; the unit of reading speed is character per second; the unit of forward saccadic length is character.

TABLE 4B | The 95\% confidence intervals of global eye movement measure under four conditions.

\begin{tabular}{|c|c|c|c|c|c|c|c|c|c|}
\hline & & \multicolumn{2}{|c|}{ Unspaced format } & \multicolumn{2}{|c|}{ Inter-character spaced format } & \multicolumn{2}{|c|}{ Inter-word spaced format } & \multicolumn{2}{|c|}{ Non-word spaced format } \\
\hline & & Lower & Upper & Lower & Upper & Lower & Upper & Lower & Upper \\
\hline \multirow[t]{2}{*}{ Mean fixation duration } & $F_{1}$ & 252 & 268 & 229 & 244 & 228 & 244 & 235 & 251 \\
\hline & $F_{2}$ & 256 & 264 & 233 & 240 & 232 & 240 & 239 & 247 \\
\hline \multirow[t]{2}{*}{ Mean saccadic length } & $F_{1}$ & 1.87 & 2.17 & 3.12 & 3.63 & 2.57 & 2,94 & 2.46 & 2.85 \\
\hline & $F_{2}$ & 1.95 & 2.08 & 3.31 & 3.46 & 2.68 & 2.83 & 2.57 & 2.75 \\
\hline \multirow[t]{2}{*}{ Number of fixations } & $F_{1}$ & 9.80 & 11.31 & 11.23 & 13.11 & 10.30 & 11.99 & 10.83 & 12.63 \\
\hline & $F_{2}$ & 10.25 & 11.02 & 11.75 & 12.62 & 10.85 & 11.47 & 11.41 & 12.19 \\
\hline \multirow[t]{2}{*}{ Total fixation duration } & $F_{1}$ & 2863 & 3376 & 3067 & 3623 & 2791 & 3338 & 3014 & 3543 \\
\hline & $F_{2}$ & 3000 & 3263 & 3188 & 3452 & 2941 & 3143 & 3156 & 3391 \\
\hline \multirow[t]{2}{*}{ Reading speed } & $F_{1}$ & 5.16 & 6.28 & 4.78 & 5.70 & 5.23 & 6.33 & 4.89 & 5.84 \\
\hline & $F_{2}$ & 5.41 & 5.94 & 5.04 & 5.46 & 5.56 & 6.00 & 5.15 & 5.59 \\
\hline \multirow[t]{2}{*}{ Forward saccadic length } & $F_{1}$ & 2.12 & 2.53 & 3.21 & 3.87 & 2.88 & 3.33 & 2.75 & 3.21 \\
\hline & $F_{2}$ & 2.17 & 2.28 & 3.30 & 3.43 & 2.94 & 3.05 & 2.82 & 2.96 \\
\hline
\end{tabular}

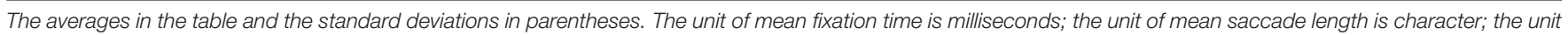

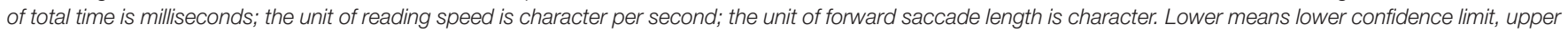
means upper confidence limit. $F_{1}$ means the subject analysis, $F_{2}$ means the item analysis.

TABLE 5 | F values, degrees of freedom, $p$ values, $\eta^{2}$ values, and post hoc comparisons for each index.

\begin{tabular}{|c|c|c|c|c|c|c|}
\hline Index & & $\boldsymbol{F}$ & $d f$ & $p$ & $\eta^{2}$ & Post hoc comparisons, $p<0.05$ \\
\hline \multirow[t]{2}{*}{ Mean fixation duration } & $F_{1}$ & 76.60 & 3,117 & $<0.001$ & 0.66 & Condition 1 > Condition 2; Condition $1>$ Condition 3; Condition $1>$ Condition 4; \\
\hline & $F_{2}$ & 25.70 & 3,177 & $<0.001$ & 0.30 & Condition 4 > Condition 2; Condition 4 > Condition 3; \\
\hline \multirow[t]{2}{*}{ Mean saccadic length } & $F_{1}$ & 209.98 & 3,117 & $<0.001$ & 0.84 & Condition 2 > Condition 1; Condition $2>$ Condition 3; Condition $2>$ Condition 4; \\
\hline & $F_{2}$ & 221.88 & 3,177 & $<0.001$ & 0.79 & Condition 3 > Condition 1; Condition 4 > Condition 1; \\
\hline \multirow[t]{2}{*}{ Number of fixations } & $F_{1}$ & 28.31 & 3,117 & $<0.001$ & 0.42 & Condition 2 > Condition 1; Condition 2 > Condition 3; Condition 4 > Condition 1; \\
\hline & $F_{2}$ & 21.96 & 3,177 & $<0.001$ & 0.27 & Condition 4 > Condition 3; Condition 3 > Condition 1; \\
\hline \multirow[t]{2}{*}{ Total fixation duration } & $F_{1}$ & 18.01 & 3,117 & $<0.001$ & 0.42 & Condition 3 < Condition 2; Condition $3<$ Condition 4; \\
\hline & $F_{2}$ & 6.05 & 3,177 & 0.001 & 0.09 & Condition $1<$ Condition 2; Condition $1<$ Condition 4; \\
\hline \multirow[t]{2}{*}{ Reading speed } & $F_{1}$ & 20.92 & 3,117 & $<0.001$ & 0.35 & Condition 3 > Condition 2; Condition 3 > Condition 4; \\
\hline & $F_{2}$ & 5.84 & 3,177 & 0.001 & 0.09 & Condition 1 > Condition 2; Condition 1 > Condition 4; \\
\hline \multirow[t]{2}{*}{ Forward saccadic length } & $F_{1}$ & 189.06 & 3,117 & $<0.001$ & 0.83 & Condition $2>$ Condition 1; Condition $2>$ Condition 3 ; Condition $2>$ Condition 4; \\
\hline & $F_{2}$ & 258.55 & 3,177 & $<0.001$ & 0.81 & Condition $3>$ Condition 1, Condition $3>$ Condition 4 ; Condition $4>$ Condition 1 ; \\
\hline
\end{tabular}

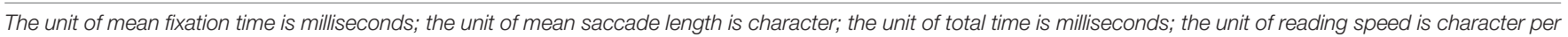

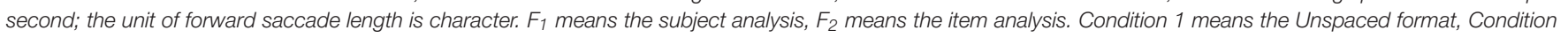
2 means the inter-character spaced format, Condition 3 means the inter-word spaced format, Condition 4 means the non-word spaced format.

difference in the total reading time between the inter-character spaced format and the non-word spaced format, $p_{s}>0.05$. This may be the interference of inter-characters offset that of nonword spaces. The difference between each of the other conditions was significant, $p_{s}<0.01$. Combined with reading speed, the main effect of word segmentation was significant on reading speed, $F_{1}(3,117)=20.92, p<0.001, \eta^{2}=0.35 ; F_{2}(3,177)=5.84$, $p=0.001, \eta^{2}=0.09$. The post-test results showed that the reading speed in the inter-word spaced format was the fastest, but was not significantly different to that in the unspaced format, 
$p_{s}>0.05$. The reading speed in the inter-character spaced format was not significantly different to that in the non-word spaced format, $p_{s}>0.05$. However, before the reading training, the reading speed in the inter-word spaced format was significantly faster than that in the unspaced format in Experiment 1, which meant the facilitation of inter-word spaces changed smaller in the Experiment 2.

Secondly, in the results on spacing indicators, we found a significant word-segmentation effect in the number of fixations: $F_{1}(3,117)=28.31, p<0.001, \eta^{2}=0.42 ; F_{2}(3,177)=21.96$, $p<0.001, \eta^{2}=0.27$. The post hoc test showed that there was significant difference between each condition, $p_{s}<0.05$. Except the comparison between the inter-character word format and the non-word format, which was not significant, $p=0.21$. The highest number of fixations was found in the inter-character spaced format, $p_{s}<0.05$. This may be because the intercharacter spaces caused reading interference in Chinese texts. Furthermore, there was a significant word-segmentation effect on the mean saccadic length: $F_{1}(3,117)=209.98, p<0.001, \eta^{2}=0.84$; $F_{2}(3,177)=221.88, p<0.001, \eta^{2}=0.79$. The post hoc test results showed the difference between inter-word spaced format and the non-word spaced format was not significantly, $p>0.05$. There was a significant difference between each of the other conditions, $p_{s}<0.01$. The mean saccadic length in the non-word spaced format was longer than that in the unspaced condition, $p_{s}<0.001$. This was because the language information per unit space was the largest under the unspaced format. Furthermore, the main effect of word segmentation on forward saccadic length was significant, $F_{1}(3,117)=189.06, p<0.001, \eta^{2}=0.83 ; F_{2}$ $(3,177)=258.55, p<0.001, \eta^{2}=0.81$. The results in post hoc test showed that the difference between each other conditions was significant, $p_{s}<0.001$. In sum, the results in the experiment 2 showed that the facilitation of word segmentation changed smaller, which supported research hypothesis.

\section{Discussion}

The purpose of Experiment 2 was to determine whether the facilitation effect of inter-word spaces would change after reading training to improve participants' familiarity with the format. Combined with the results in the Experiment 1, whether there was a trade-off between format familiarity and the facilitation effect of inter-word spaces was verified.

The results found that the difference between the inter-word spaced format and unspaced format was not significant on the total fixation duration and reading speed, which meant that the facilitation effect of inter-word spaces as word-segmentation clues changed smaller or disappeared. This is consistent with previous studies where no facilitation of inter-word spaces was found for Chinese native readers (Bai et al., 2008, 2012a; Shen et al., 2010; Yan et al., 2012). The common feature of these studies is that the participants were readers with abundant Chinese reading experience, which meant high level of format familiarity in the default Chinese text. Therefore, inter-word spaces did not facilitate the process of Chinese reading when readers had rich experience, that is in the familiar format. In Experiment 2, because reverse-order reading training increased participants' relevant reading experience, the unfamiliarity of the reverse-order format changed to format familiarity. In a familiar format, the inter-word spaces as word-segmentation clues did not facilitate Chinese reading. The results supported the research hypothesis in Experiment 2: after increasing participants' familiarity with the format, the facilitation effect of inter-word spaces in Chinese reading changed smaller. There is the other possible explanation, which is "floor effect," the subjects have reached the best reading performance after reading training in the experiment 2, the inter-word spaces could not facilitate the best reading performance. The "floor effect" may be explain the findings in experiment 2 , which could not explain why there is facilitation of inter-word spaces on unfamiliar format in the experiment 1 for Chinese native readers, who also have the best reading ability and best reading performance. The Chinese reading ability would not disappear for just reversing the reading direction. Of course, the "floor effect" should be investigated in the further research via reading training of inter-word spaces for the other subjects.

The combined results of Experiment 1 and Experiment 2 show that there was indeed a trade-off between format unfamiliarity and the facilitation effect of inter-word spaces in Chinese reading, which verified the research assumption (Bai et al., 2008).

\section{SUPPLEMENTARY ANALYSIS}

The facilitation effect of inter-word spaces in a familiar format was examined in Experiment 1 and that in an unfamiliar format was examined in Experiment 2. Combining Experiment1 and Experiment 2, supplementary analysis was conducted to investigate the role of word segmentation and format familiarity in Chinese reading. A repeated-analysis measurement was conducted: 4 (word segmentation: unspaced condition, intercharacter spaced condition, inter-word spaced condition, nonword spaced condition) $* 2$ (format familiarity: unfamiliar format and familiar format). The analysis are shown in Table 6.

The main effect of word segmentation was significant on the mean fixation duration, $F_{1}(3,234)=133.58, p<0.001$, $\eta_{p}{ }^{2}=0.63 ; F_{2}(3,177)=94.27, p<0.001, \eta_{p}{ }^{2}=0.62$; the main effect of format familiarity on the mean fixation duration was not significant, $F_{1}(1,78)=0.02, p>0.1 ; F_{2}(1,59)=2.902, p=0.09$; the interaction between word segmentation and format familiarity was not significant, $F_{1}(3,234)=1.88, p>0.1 ; F_{2}(3,177)=0.824$, $p>0.1$. See Figure 1 .

The main effect of word segmentation on the mean saccadic length was significant, $F_{1}(3,234)=382.85, p<0.001, \eta_{p}{ }^{2}=0.83$; $F_{2}(3,177)=300.42, p<0.001, \eta_{p}^{2}=0.84$; the main effect of format familiarity was significant, $F_{1}(1,78)=22.40, p<0.001$, $\eta_{p}{ }^{2}=0.22 ; F_{2}(1,59)=1590.65, p<0.001, \eta_{p}^{2}=0.96$; the interaction between word segmentation and reading training was significant, $F_{1}(3,234)=9.37, p<0.001, \eta_{p}{ }^{2}=0.11 ; F_{2}$ $(3,177)=8.91, p<0.001, \eta_{p}^{2}=0.13$. See Figure 2. A simpleeffects analysis found that the main effect of word segmentation on the unfamiliar format was significant, $F_{1}(3,76)=139.16$, $p<0.001, \eta_{p}{ }^{2}=0.85 ; F_{2}(3,57)=155.64, p<0.001, \eta_{p}{ }^{2}=0.89$. In the unfamiliar format, there was a significant difference between each condition $\left(p_{s}<0.01\right)$. On the other hand, there was a 
TABLE $6 \mid F$ values, $p$ values, $\eta_{P}^{2}$ values of word segmentation and format familiarity and that of Interaction for each index.

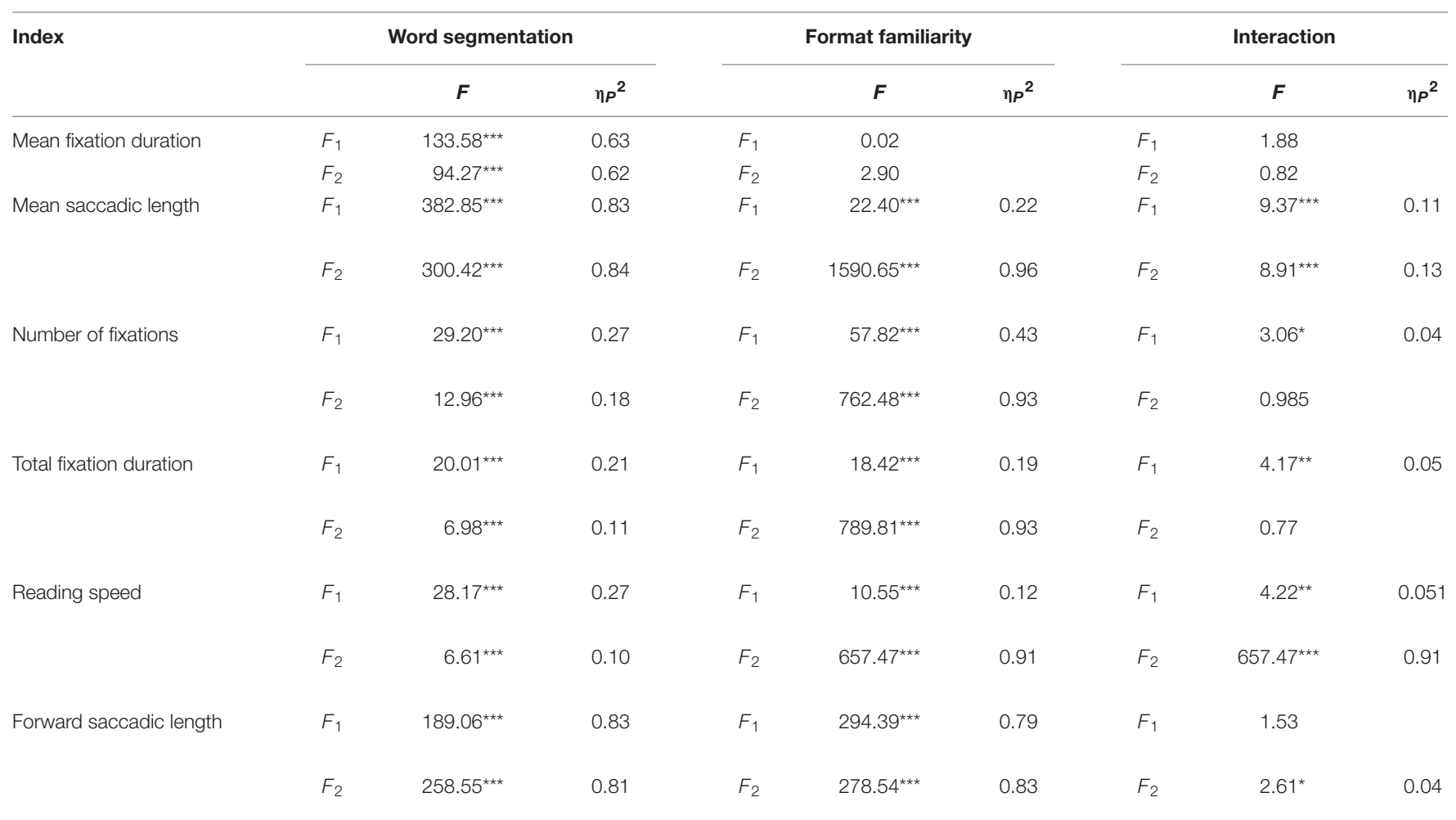

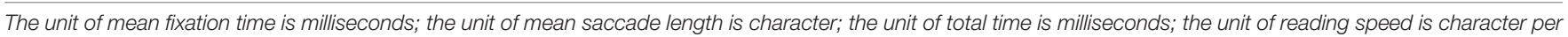

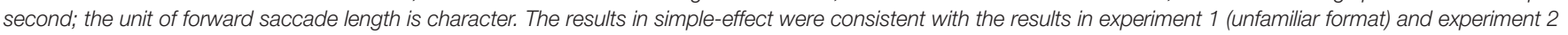
(familiar format), which not be included in the Table 6. ${ }^{\star * *}$ Means $P<0.001$, ${ }^{\star *}$ Means $P<0.01$, ${ }^{\star}$ Means $P<0.05$.

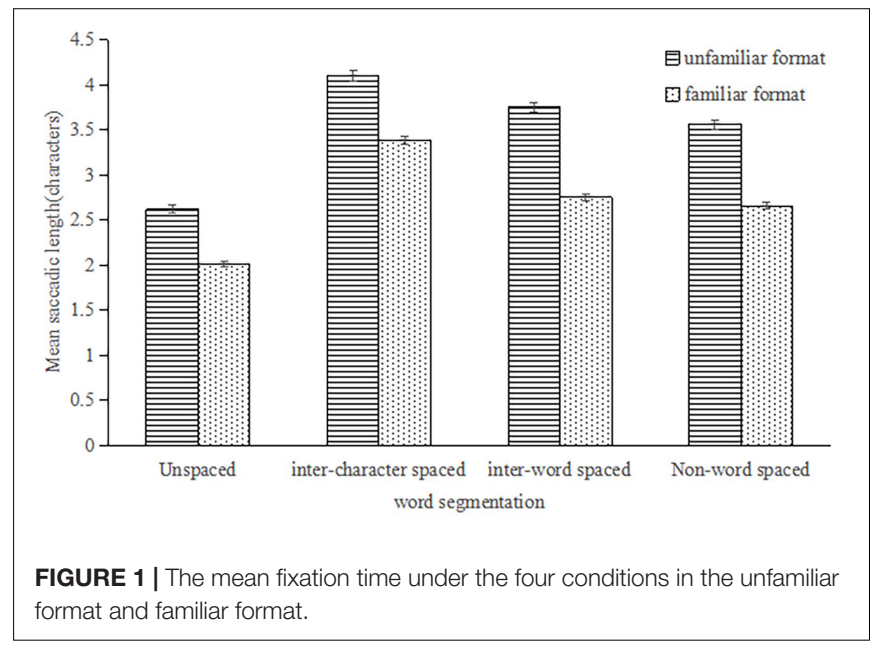

significant difference between the four conditions in the familiar format, $F_{1}(3,76)=81.83, p<0.001, \eta_{p}{ }^{2}=0.76, F_{2}(3,57)=327.16$, $p<0.001, \eta_{p}^{2}=0.95$. There was only one difference in the familiar format, where the difference between inter-word spaced format and non-word spaced format was not significant, $p=0.24$. This meant the interference of non-word and facilitation of inter-word reduced were decreased at the same time on the familiar format.

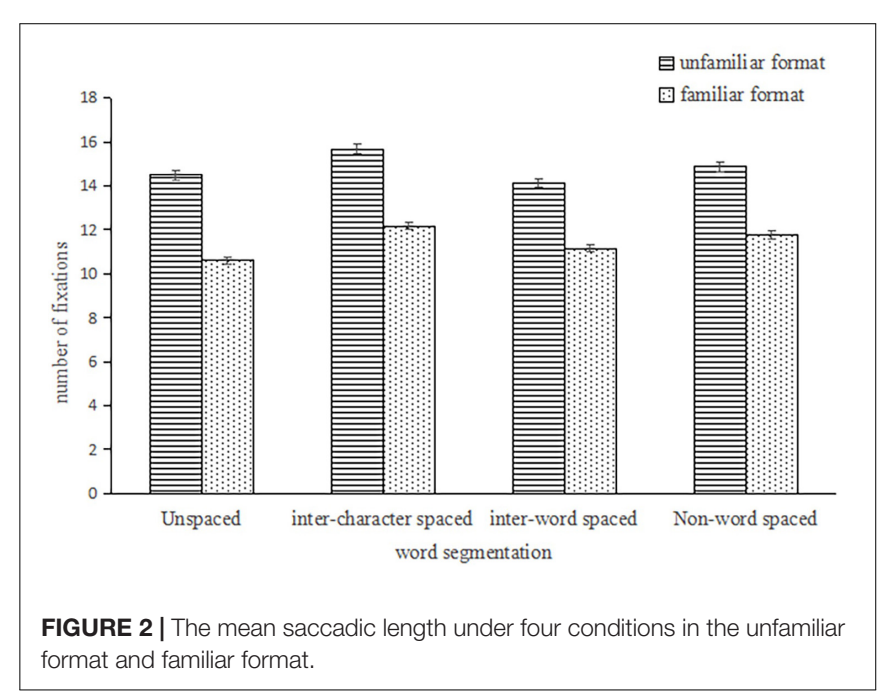

There was a significant word-segmentation effect $\left[F_{1}(3,234)=29.198, p<0.001, \eta_{p}^{2}=0.27 ; F_{2}(3,177)=12.96\right.$, $\left.p<0.001, \eta_{p}^{2}=0.18\right]$ and a significant format-familiarity effect $\left[F_{1}(1,78)=57.82, p<0.001, \eta_{p}^{2}=0.43 ; F_{2}(1,59)=762.48\right.$, $\left.p<0.001, \eta_{p}^{2}=0.93\right]$ on the number of fixations. The interaction was significant on the subjective analysis, $F_{1}$ $(3,234)=3.06, p<0.05, \eta_{p}^{2}=0.04 ; F_{2}(3,177)=0.985, p=0.401$. 
See Figure 3. The simple-effects analysis found that there was a significant word-segmentation effect on the unfamiliar format, $F_{1}(3,76)=16.25, p<0.001, \eta_{p}^{2}=0.39 ; F_{2}(3,57)=4.14, p=0.01$, $\eta_{p}{ }^{2}=0.18$. The subject-analysis results showed that the number of fixations in the inter-character spaced condition was larger than the other conditions $\left(p_{s}<0.01\right)$. However, there was no significant difference between the unspaced condition and the inter-word spaced condition $(p=1.00)$, and the difference between the unspaced and the non-word spaced conditions was not significant $(p=0.60)$. There were significant differences between each of other conditions $\left(p_{s}<0.01\right)$. The item analysis results were not totally consistent with those of the subject analysis. Firstly, there was no significance between the unspaced condition and the inter-character spaced condition $(p=0.14)$. Secondly, there was not significant between the inter-character spaced and non-spaced condition $(p=1.00)$. On the other hand, there was a significant word-segmentation effect on the familiar format, $F_{1}(3,76)=16.42, p<0.001, \eta_{p}^{2}=0.39 ; F_{2}(3,57)=16.51$, $p<0.001 . \eta_{p}{ }^{2}=0.47$. The subject-analysis results showed that the number of fixations in the inter-character spaced condition was the largest, with no significant difference with that in the non-word spaced condition $(p=0.23)$. At the same time, there was no significant difference between the unspaced condition and the inter-word spaced condition $(p=0.12)$. There were significant differences between each other condition $\left(p_{s}<0.05\right)$. The item analysis results were not totally consistent with those of the subject analysis. Firstly, there was no significant difference between the unspaced condition and the inter-character spaced condition $(p=0.23)$. There were significant differences between each of the other conditions $\left(p_{s}<0.05\right)$.

The main effect of word segmentation $\left[F_{1}(3,231)=20.01\right.$, $\left.p<0.001, \eta_{p}{ }^{2}=0.21 ; F_{2}(3,177)=6.98, p<0.001, \eta_{p}{ }^{2}=0.11\right)$ and format-familiarity $\left[F_{1}(1,77)=18.42, p<0.001, \eta_{p}^{2}=0.19\right.$; $\left.F_{2}(1,59)=789.81, p<0.001, \eta_{p}{ }^{2}=0.93\right]$ on the total fixation duration were significant. The interaction was significant in the subject analysis but not in the item analysis, $F_{1}(3,231)=4.17$, $p<0.01, \eta_{p}^{2}=0.05 ; F_{2}(3,177)=0.77, p=0.51$. See Figure 4. A simple-effects analysis found the main effect of word segmentation was significant in the unfamiliar format,

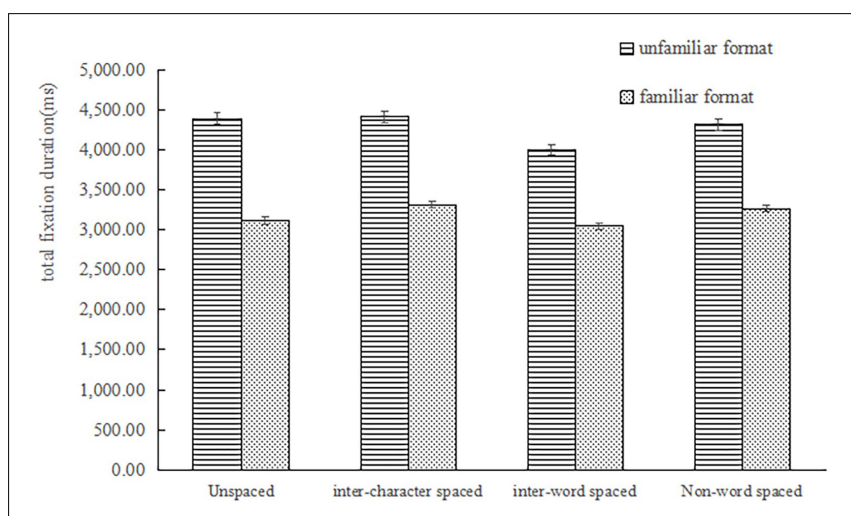

FIGURE 3 | The number of fixations under four conditions in the unfamiliar format and familiar format.

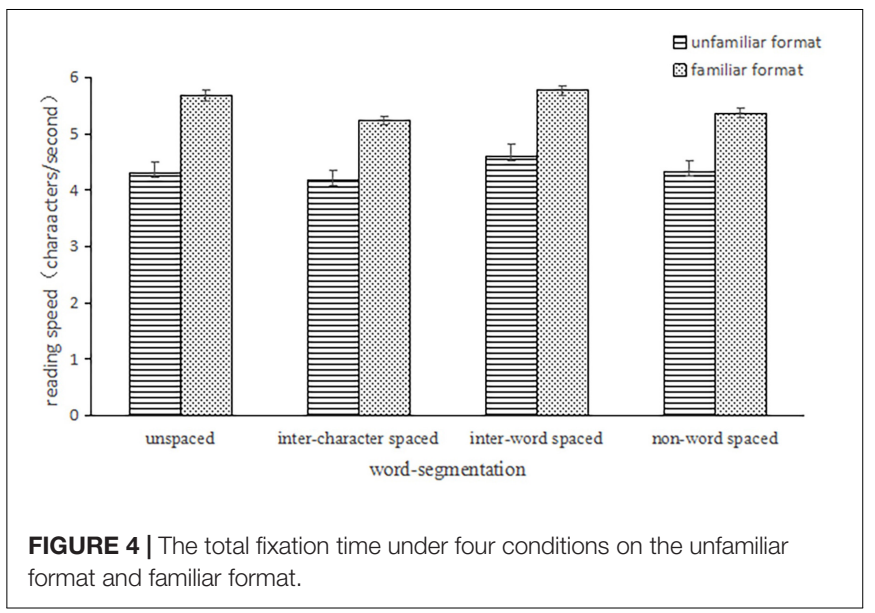

$F_{1}(3,75)=14.71, p<0.001, \eta_{p}^{2}=0.37$. The difference between unspaced format and inter-character spaced format was not significant $(p=1.00)$, and that between unspaced format and non-spaced format was not significant $(p=1.00)$. These difference was significant $(p=0.008)$ or marginally significant $(p=0.06)$ in the experiment 2 , which meant the interference of inter-character spaces and non-word spaces was appeared on the familiar format. Interestingly, the facilitation of interword spaces changed smaller in the familiar format. The total fixation duration under the inter-word spaced format was the significantly shortest $\left(p_{s}<0.001\right)$. However, the difference between the inter-word spaced format and unspaced format was not significant on the familiar format $(p=1.00)$. The other results under familiar format were consistent with the results under unfamiliar format.

The main effect of word segmentation $\left[F_{1}(3,234)=28.17\right.$, $\left.p<0.001, \eta_{p}^{2}=0.27 ; F_{2}(3,177)=6.61, p<0.001, \eta_{p}^{2}=0.10\right]$ and format-familiarity $\left[F_{1}(1,78)=10.55, p<0.001, \eta_{p}^{2}=0.12\right.$; $\left.F_{2}(1,59)=657.47, p<0.001, \eta_{p}^{2}=0.91\right]$ on reading speed were significant. The interaction was significant in the subject analysis but not on the item analysis, $F_{1}(3,234)=4.22$, $p<0.01, \eta_{p}^{2}=0.051 ; F_{2}(3,177)=0.68, p>0.1$. See Figure 5. Simple-effects analysis found the main effect of word segmentation was significant in the unfamiliar format, $F_{1}(3$, 76) $=12.25, p<0.001, \eta_{p}{ }^{2}=0.33$; the subject-analysis results found the reading speed in the inter-word spaced condition was significantly faster than the other conditions, $p_{s}<0.001$. The difference between unspaced format and inter-word spaced format was no more significant under familiar format $(p=1.00)$, which implied that the facilitation of word segmentation was changed smaller. Interestingly, the difference between the unspaced format and inter-character spaced format was not significant under unfamiliar format, which was significant under familiar format. This implied that the interference of intercharacter spaces only appeared under the familiar format. On the other hand, there was significant differences under familiar format, $F_{1}(3,76)=19.46, p<0.001, \eta_{p}{ }^{2}=0.43$. The subjectanalysis results showed that the difference in the unspaced and inter-word spaced condition was not significant, which means 


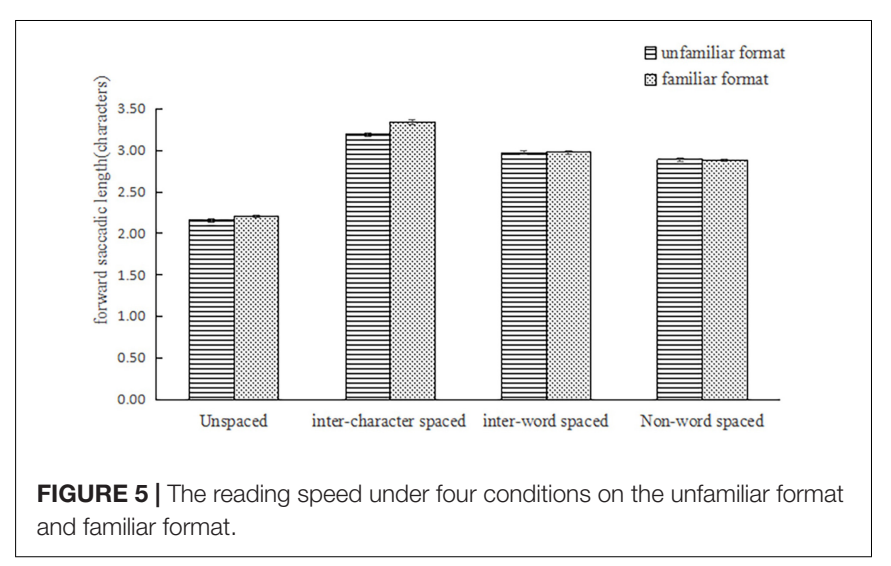

that the facilitation of word segmentation changed smaller under familiar format.

The main effect of word-segmentation conditions $\left[F_{1}(3,234)=294.39, p<0.001, \eta_{p}^{2}=0.79 ; F_{2}(3,177)=278.54\right.$, $\left.p<0.001, \eta_{p}^{2}=0.83\right]$ on forward saccadic length was significant; however, it was not significant on format-familiarity $\left[F_{1}\right.$ $\left.(1,78)=0.000, p>0.1 ; F_{2}(1,59)=11.27, p=0.001, \eta_{p}{ }^{2}=0.16\right]$. The interaction was not significant in the subject analysis, but was marginally significant in the item analysis, $F_{1}(3,234)=1.53$, $p>0.1 ; F_{2}(3,177)=2.61, p=0.05, \eta_{p}{ }^{2}=0.04$. See Figure 6 . Simple-effects analysis found that the main effect of word segmentation was significant in the unfamiliar format, $F_{2}(3$, $116)=279.94, p<0.001$. The subject-analysis results found that the difference was significant in the other conditions $\left(p_{s}<0.001\right)$ except for the inter-word spaced and non-word spaced conditions $(p>0.05)$.

\section{GENERAL DISCUSSION}

This study aimed at investigating whether there was a trade-off between format familiarity and word-segmentation facilitation in Chinese reading. The reading training was manipulated to control the format familiarity, and EyeLink 1000 (SR Research, Canada) was used to record the eye tracking of adult participants in four word-segmentation conditions. The results showed there was a trade-off between format unfamiliarity and wordsegmentation facilitation in Chinese reading.

Based on this, the primary task for readers is to segment words in unspaced texts in Chinese reading. However, a consensus has not been reached over whether inserting spaces between words facilitates Chinese reading. Bai et al. (2008) did not find that inter-word spaces facilitated the reading of native Chinese undergraduates, which was explained on the basis of a trade-off between inter-word spaces and format familiarity. The facilitating effect was offset by the format unfamiliarity of inter-word spaces. However, in the unspaced condition, where there was neither facilitation of word segmentation or format unfamiliarity, and there was no significant difference in reading performance. Therefore, the format familiarity was controlled in Experiment 1. For readers, the unspaced format and interword spaced format in the Chinese reverse texts read from

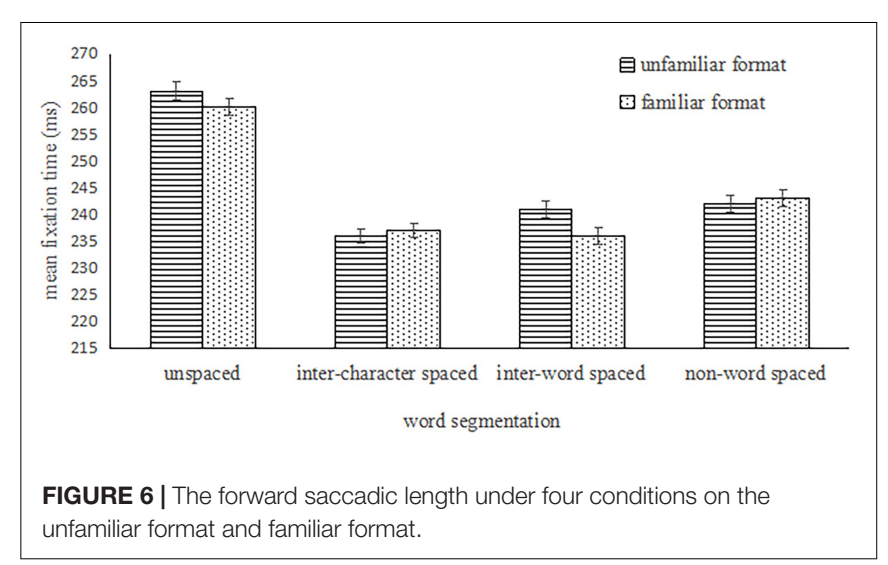

right to left were unfamiliar formats. The results showed that inter-word spaces facilitated reading in the unfamiliar format, where the reading speed in the inter-word spaced condition was faster than that in the unspaced condition. The results supported the prior assumption and were consistent with the research hypothesis. Based on this finding, Experiment 2 was designed to investigate whether the facilitation effect would change, that was disappear or reduce. We improved participants' familiarity with the unspaced text format which was just like normal Chinese texts via reading reverse Chinese texts for $30 \mathrm{~min}$ per day for 10 days. In Experiment 2, the eye tracking of new participants reading the Chinese sentences was recorded; the reason for changing the participants was to retain the same Chinese sentences in the eyemovement experiment. Surprisingly, the results found that there was no significant difference between the reading speed and total fixation time in the unspaced and inter-word spaced conditions. This meant that the facilitation effect of inter-word spaces as word-segmentation indicators changed smaller. The combined results in Experiment 1 and Experiment 2 showed a trade-off between format familiarity and word-segmentation facilitation in Chinese reading.

The default format of the reading and writing system in contemporary Chinese language is from left to right, which is regarded as a familiar format by native Chinese readers. There is a trade-off between format familiarity and the facilitation effect of inter-word spaces in Chinese reading; native Chinese readers have a high level of format familiarity, and so the facilitation of word segmentation did not appear as in prior studies (Bai et al., 2008; Shen et al., 2010; Li et al., 2011b; Yan et al., 2012). The common feature of these previous studies was that the participants had sufficient reading experience to offset the wordsegmentation facilitation. This provides a reasonable explanation for this finding. On the other hand, the previous studies which found that inter-word spaces facilitated Chinese reading had a common feature; that is, the participants who were foreign undergraduates or Chinese children with dyslexia had insufficient Chinese reading experience. Lack of Chinese reading experience caused format unfamiliarity, which could not offset the interword facilitation. Therefore, there was word-segmentation facilitation of the Chinese reading process in these studies (Bai et al., 2009, 2011; Wang et al., 2010; Blythe et al., 2012; 
Shen et al., 2012; Gu et al., 2017). The inconsistency of wordsegmentation facilitation comes from having sufficient Chinese reading experience. The reverse Chinese texts presented single characters from right to left, and then the readers needed to read from right to left in an unfamiliar format. Therefore, this study used the reading training of reverse Chinese texts in an unfamiliar format, which improved the relevant reading experience for readers. In Experiment 2, the results showed that the facilitation effect of inter-word spaces found in Experiment 1 changed smaller via improving the participants' familiarity with the format of reverse Chinese texts. In sum, the results supported the research hypothesis.

In addition, the trade-off can also explain the assumption in the previous studies, which proposed that inter-word spaces could play a certain role in promoting Chinese reading of difficult or ambiguous texts (Hsu and Huang, 2000; Inhoff et al., 2000; Inhoff and Radach, 2002; Li et al., 2011a). Hsu and Huang (2000) found that inter-word spaces as word-segmentation indicators help readers to achieve faster word recognition and reading comprehension compared with unspaced texts. Compared with the default format, the readers have to pay a higher reading cost to process the reverse Chinese texts, where the reading difficulty was higher. This means that the inter-word spaces could facilitate Chinese reading in difficult texts.

The combined results in Experiment 1 and Experiment 2 showed that a trade-off between format unfamiliarity and wordsegmentation facilitation of Chinese reading did indeed exist. For unspaced Chinese texts, word segmentation did not depend on the low-level visual clues. The mechanisms behind the trade-off were the low-level visual factor (format familiarity) and the high-level cognition factor (reading experience). The mechanism can be explained by the holistic hypothesis of the computational model on the word-segmentation mechanism in Chinese reading (Li et al., 2009). Two assumptions were included in the model: feed-forward assumption and holistic hypothesis. The first assumption supported the process whereby the character recognition system obtains visual information from characters and then transfers it to the word-segmentation stage, and finally integrates it into the word-recognition stage. There is only feedforward from bottom to top and no feedback from top to bottom in word processing. However, the holistic hypothesis supports the notion that the visual information system, character recognition system and word-recognition system affect the wordsegmentation stage and word-recognition stage interactively. Previous studies supported the holistic assumption being suitable for Chinese reading, which is consistent with the results in this study (Li et al., 2009, 2011a; Ma, 2017; Ma and Zhuang, 2018). Based on the holistic hypothesis, the inter-word spaces as low-level visual information affect reading comprehension from bottom to top, while the reading experience as a highlevel cognition factor affects reading comprehension from top to bottom. Therefore, the reading experience as a high-level cognitive factor behind format familiarity and inter-word spaces as a low-level visual factor would both affect the Chinese reading, with a trade-off between them. The assumption explained that there was no facilitation effect of inter-word spaces in the previous studies, where the participants were native adults with rich Chinese reading experiences (Bai et al., 2008; Shen et al., 2010; Yan et al., 2012; Liu and Li, 2014). The richness of Chinese reading experiences affected the facilitation of interword spaces as the low-level visual clues in word recognition and reading comprehension. However, previous studies of foreign students who learned Chinese as a second language found that the inter-word spaces facilitated reading speed and prompted word recognition as well as reading comprehension. This is because Chinese learning beginners had insufficient Chinese reading experience, and the inter-word spaces could help them to segment word from Chinese texts, so as to acquire faster reading comprehension and word recognition (Wang et al., 2010; Shen et al., 2012; Gu et al., 2017; Zhou et al., 2020).

In the current study, the reading training just contained unspaced reverse texts to improve the format familiarity. Further research could focus on improving the format familiarity of inter-word spaced text via reading training in Chinese reverse texts where spaces have been inserted between words. Whether the facilitation effect of inter-word spaces would appear after improving the format familiarity of inter-word spaced text needs to be further verified. In addition, future studies could manipulate the inter-word spaces, word frequency and format familiarity to explore the relationship between them and examine the mechanism between word segmentation and word recognition. Moreover, The expect direction is the tradeoff during learning a new language in the future, especially for non-native readers, when they start to learn Chinese which is not familiar orthography and semantic information, the format familiarity may have more influence on the facilitation of the inter-word spaces. For example, Uyghur whose mother tongue is presented from right to left start to learn Chinese, however, they are unfamiliar with the Chinese format from left to right. The reading performance of Uyghur and that of Chinese could be compared to expect new surprising findings.

\section{CONCLUSION}

To summarize, the results indicate that inter-word spaces as low-level visual clues facilitate Chinese reading in an unfamiliar format. After improving participants' familiarity with the format, the facilitation effect of inter-word spaces changed smaller. There is a trade-off between format familiarity and facilitation of inter-word spaces, which supported the assumption made in previous studies.

\section{DATA AVAILABILITY STATEMENT}

The original contributions presented in the study are included in the article/Supplementary Material, further inquiries can be directed to the corresponding author/s.

\section{ETHICS STATEMENT}

Based on the Declaration of Helsinki (BMJ 1991; 302: 1194), Tianjin Normal University's Medical Ethical Committee 
approved the experiment. The patients/participants provided their written informed consent to participate in this study.

\section{AUTHOR CONTRIBUTIONS}

$\mathrm{XB}$ provided the research idea and the research construction. $\mathrm{MC}$ and $\mathrm{YW}$ designed the experiments and wrote the manuscript. MC conducted the data analysis. BZ participated the eye-movement experiment. XL contributed to writing the manuscript. All authors contributed to the article and approved the submitted version.

\section{REFERENCES}

Bai, X., Guo, Z., Cao, Y., Gu, J., Yan, G., and Zang, C. (2012a). Effects of word segmentation on hindi-english bilinguals reading:evidence from eye movements. [词切分对印-英双语者阅读影响的眼动研究]. J. Psychol. Sci. 35, 544-549.

Bai, X., Liang, F., Yan, G., Tian, J., Zang, C., and Meng, H. (2012b). Inter-word space effects on saccadic target selection in chinese reading: evidence from second language learners. [阅读障碍儿童与其年龄和能力匹配儿童阅读空格文本的注视位置效应]. Acta Psychol. Sin. 44, 853-867.

Bai, X., Li, X., and Yan, G. (2015). Eye movement control in chinese reading: a summary of 20-years research. Psychol. Dev. Educ. 31, 85-91.

Bai, X., Meng, H., Wang, J., Tian, J., Zang, C., and Yan, G. (2011). The landing positions of dyslexic,age-matched and ability-matched children during reading spaced text. [词边界信息在中文阅读眼跳目标选择中的作用:来自中文二语学习者的证据]. Acta Psychol. Sin. 43, 851-862.

Bai, X., Tian, J., Yan, G., and Wang, T. L. (2009). An eye movement study:the role of word segmentation on chinese reading for American college students. Nan Kai Linguist. 1, 140-153.

Bai, X., Zhang, M., Zang, C., Li, X., Chen, L., and Yan, G. (2014). The effect of word boundary information on chinese word acquisition and recognition: evidence from eye movements. [词边界信息在中文词汇学习与识别中的作用:眼动研究的证据]. Adv. .Psychol. Sci. 22, 1-8.

Bai, X. J., Yan, G. L., Liversedge, S. P., Zang, C. L., and Rayner, K. (2008). Reading spaced and unspaced chinese text: Evidence from eye movements. J. Exp. Psychol. Hum. Percept. Perform. 34, 1277-1287. doi: 10.1037/0096-1523.34.5. 1277

Bassetti, B. (2009). Effects of adding interword spacing on chinese reading: a comparison of chinese native readers and English readers of chinese as a second language. Appl. Psycholinguist. 30, 757-775. doi: 10.1017/s0142716409990105

Blythe, H. I., Liang, F., Zang, C., Wang, J., Yan, G., Bai, X., et al. (2012). Inserting spaces into chinese text helps readers to learn new words: an eye movement study. J. Mem. Lang. 67, 241-254. doi: 10.1016/j.jml.2012.05.004

Cui, L., Drieghe, D., Bai, X., Yan, G., and Liversedge, S. P. (2014). Parafoveal preview benefit in unspaced and spaced chinese reading. Q. J. Exp. Psychol. 67, 2172-2188.

Deutsch, A., and Rayner, K. (1999). Initial fixation location effects in reading Hebrew words. Lang. Cogn. Process. 14, 393-421. doi: 10.1080/ 016909699386284

Gu, J. J., Zhang, Y., and Zheng, H. Y. (2017). An eye movement study: the role of word segmentation for Russian students on chinese reading. Psychol. Res. 10, 22-29.

Henderson, J. M., and Ferreira, F. (1990). Effects of foveal processing difficulty on the perceptual span in reading - implications for attention and eye-movement control. J. Exp. Psychol. Learn. Mem. Cogn. 16, 417-429. doi: 10.1037/02787393.16.3.417

Hsu, S. H., and Huang, K. C. (2000). Interword spacing in chinese text layout. Percept. Mot. Skills 91, 355-365. doi: 10.2466/pms.91.6.355-365

Inhoff, A. W., and Liu, W. M. (1998). The perceptual span and oculomotor activity during the reading of chinese sentences. J. Exp. Psychol. Hum. Percept. Perform. 24, 20-34. doi: 10.1037/0096-1523.24.1.20

Inhoff, A. W., and Radach, R. (2002). The role of spatial information in the reading of complex words. Comments Theor. Biol. 7, 121-138.

\section{FUNDING}

Ministry of Education, Humanities and Social Sciences Research Youth Project, China, 18YJC190023.

\section{SUPPLEMENTARY MATERIAL}

The Supplementary Material for this article can be found online at: https://www.frontiersin.org/articles/10.3389/fpsyg. 2021.602931/full\#supplementary-material

Inhoff, A. W., Radach, R., and Heller, D. (2000). Complex compounds in German: Interword spaces facilitate segmentation but hinder assignment of meaning. J. Mem. Lang. 42, 23-50. doi: 10.1006/jmla.1999.2666

Irwin, D. E. (1998). Lexical processing during saccadic eye movements. Cogn. Psychol. 36, 1-27. doi: 10.1006/cogp.1998.0682

Li, X., Bicknell, K., Liu, P., Wei, W., and Rayner, K. (2014). Reading is fundamentally similar across disparate writing systems: a systematic characterization of how words and characters influence eye movements in chinese reading. J. Exp. Psychol. Gen. 143, 895-913. doi: 10.1037/a0033580

Li, X., Liu, P., and Ma, G. (2011a). Advances in cognitive mechanisms of word segmentation during chinese reading. [中文阅读中词切分的认知机理述评]. Adv. Psychol. Sci. 19, 459-470.

Li, X., Liu, P., and Rayner, K. (2011b). Eye movement guidance in chinese reading: Is there a preferred viewing location? Vis. Res. 51, 1146-1156. doi: 10.1016/j. visres.2011.03.004

Li, X., and Pollatsek, A. (2011). Word knowledge influences character perception. Psychon. Bull. Rev. 18, 833-839. doi: 10.3758/s13423-011-0115-8

Li, X., Rayner, K., and Cave, K. (2009). On the segmentation of chinese words during reading. Cogn. Psychol. 58, 525-552. doi: 10.1016/j.cogpsych.2009.02. 003

Li, Y., Huang, R., Hua, H., and Li, X. (2017). How do readers select the saccade targets? [ [阅读中的眼跳目标选择问题]. Adv. Psychol. Sci. 25, 404-412.

Liang, F., Blythe, H. I., Bai, X., Yan, G., Li, X., Zang, C., et al. (2017). The role of character positional frequency on chinese word learning during natural reading. PLoS One 12:e0187656. doi: 10.1371/journal.pone.0187656

Liu, P., and Li, X. (2014). Inserting spaces before and after words affects word processing differently in chinese: evidence from eye movements. Br. J. Psychol. 105, 57-68. doi: 10.1111/bjop.12013

Liu, P., and Lu, Q. (2018). The effects of spaces on word segmentation in chinese reading: Evidence from eye movements. J. Res. Read. 41, 329-349. doi: 10.1111/ 1467-9817.12106

Liu, Z., Pan, Y., Tong, W., and Liu, N. (2017). Effects of adults aging on word encoding in reading chinese: evidence from disappearing text. Peerj 5:e2897. doi: $10.7717 /$ peerj. 2897

Ma, G. (2017). Does interword spacing influence lexical processing in chinese reading? Vis. Cogn. 25, 815-824. doi: 10.1080/13506285.2017.1338322

Ma, G., and Zhuang, X. (2018). Distributional analyses of word frequency effects in chinese sentence reading and lexical decision tasks. J. Res. Read. 41, S183-S196. doi: $10.1111 / 1467-9817.12259$

Perea, M., and Acha, J. (2009). Space information is important for reading. Vis. Res. 49, 1994-2000. doi: 10.1016/j.visres.2009.05.009

Rayner, K. (1998). Eye movements in reading and information processing: 20 years of research. Psychol. Bull. 124, 372-422. doi: 10.1037/0033-2909.124.3.372

Rayner, K. (2009). Eye movements and attention in reading, scene perception, and visual search. Q. J. Exp. Psychol. 62, 1457-1506. doi: 10.1080/ 17470210902816461

Rayner, K., Fischer, M. H., and Pollatsek, A. (1998). Unspaced text interferes with both word identification and eye movement control. Vis. Res. 38, 1129-1144. doi: 10.1016/s0042-6989(97)00274-5

Rayner, K., Liversedge, S. P., and White, S. J. (2006). Eye movements when reading disappearing text: the importance of the word to the right of fixation. Vis. Res. 46, 310-323. doi: 10.1016/j.visres.2005.06.018 
Rayner, K., Yang, J., Castelhano, M. S., and Liversedge, S. P. (2011). Eye movements of older and younger readers when reading disappearing text. Psychol. Aging 26, 214-223. doi: 10.1037/a0021279

Reichle, E. D., Rayner, K., and Pollatsek, A. (1999). Eye movement control in reading: accounting for initial fixation locations and refixations within the E-Z Reader model. Vis. Res. 39, 4403-4411. doi: 10.1016/s0042-6989(99)00152-2

Shen, D-L., Bai, X-J., Zang, C-L., Yan, G-L., Feng, B-C., and Fan, X-H. (2010). Effect of word segmentation on beginners' reading: evidence from eye movements. [词切分对初学者句子阅读影响子阅读影响的眼动研究]. Acta Psychol. Sin. 42, 159-172.

Shen, D., Liversedge, S., Tian, J., Zang, C., Cui, L., Bai, X., et al. (2012). Eye movements of second language learners when reading spaced and unspaced chinese text. J. Exp. Psychol. Appl. 18, 192-202. doi: 10.1037/a0027485

Wang, J., Tian, J., Zang, C., and Bai, X. (2010). "Spaced chinese text reading in chinese developmental dyslexic children," in Proceedings of the Poster Session Presented at the 4th China International Conference on Eye Movement, Tianjin.

Wang, Y., Zhao, B., Chen, M., Li, X., Yan, G., and Bai, X. (2018). Influence of the frequency of fixated words and the number of strokes of parafoveal words on saccadic target selection in chinese reading. [中央凹加工负荷与副中央凹信息在汉语阅读眼跳目标选择中的作用]. Acta Psychol. Sin. 50, 13361345.

Yan, G., and Bai, X. (2000). A study of eye movement in chinese reading process. Dev. Psychol. 8, 19-22.

Yan, G., and Bai, X. (2007). Eye movement studies of chinese reading. [汉语阅读的眼动研究]. Stud. Psychol. Behav. 5, 229-234.

Yan, G., Tian, H., Bai, X., and Rayner, K. (2006). The effect of word and character frequency on the eye movements of chinese readers. Br. J. Psychol. 97, 259-268. doi: 10.1348/000712605x70066

Yan, G., Xiong, J., Zang, C., Yu, L., Cui, L., and Bai, X. (2013). Review of eyemovement measures in reading research. [阅读研究中的主要眼动指标评述]. Adv. Psychol. Sci. 21, 589-605.
Yan, G., Zhang, L., Bian, Q., and Xu, Z. (2012). Effect of word segmentation on good readers and poor readers: evidence from eye movements. Psychol. Explor. 32, 525-530.

Yan, M., Kliegl, R., Richter, E. M., Nuthmann, A., and Shu, H. (2010). Flexible saccade-target selection in chinese reading. Q. J. Exp. Psychol. 63, 705-725. doi: 10.1080/17470210903114858

Yu, M., Yan, H., and Yan, G. (2018). Is the word the basic processing unit in chinese sentence reading: an eye movement study. Lingua 205, 29-39. doi: 10.1016/j.lingua.2017.12.013

Zang, C., Liang, F., Bai, X., Yan, G., and Liversedge, S. P. (2013). Interword spacing and landing position effects during chinese reading in children and adults. J. Exp. Psychol. Hum. Percept. Perform. 39, 720-734. doi: 10.1037/a003 0097

Zang, C., Wang, Y., Bai, X., Yan, G., Drieghe, D., and Liversedge, S. P. (2016). The use of probabilistic lexicality cues for word segmentation in chinese reading. Q. J. Exp. Psychol. 69, 548-560. doi: 10.1080/17470218.2015.1061030

Zhou, W., Ye, W., and Yan, M. (2020). Alternating-color words facilitate reading and eye movements among second-language learners of chinese. Appl. Psycholinguist. 41, 685-699. doi: 10.1017/s0142716420000211

Conflict of Interest: The authors declare that the research was conducted in the absence of any commercial or financial relationships that could be construed as a potential conflict of interest.

Copyright (c) 2021 Chen, Wang, Zhao, Li and Bai. This is an open-access article distributed under the terms of the Creative Commons Attribution License (CC BY). The use, distribution or reproduction in other forums is permitted, provided the original author(s) and the copyright owner(s) are credited and that the original publication in this journal is cited, in accordance with accepted academic practice. No use, distribution or reproduction is permitted which does not comply with these terms. 


\section{APPENDIX}

\section{Examples of Reading Materials in Experiment 2}

\section{手到剪心小 1}

怎可己自到剪, 下放快, 䒝宗祖小: 了坏吓奶奶的他顾照把可, 刀剪起拿次一第子孩 。刀剪了下放地乘乘子孩? 了得么 准正，刀剪和笔画、纸来找地奋兴子孩，后之家回，工手了教师老，了园儿幼上子孩 要你, 险危太, 刀剪么什玩子孩小：刀剪的中手子孩了过夺把一, 了现出妈妈, 时纸剪备 一。来起多课工手, 了学上子孩。妈妈了给交刀剪将地悻悻子孩。剪你帮妈妈, 公什做 见看爸爸, 刀剪起拿刚子孩。妈妈给送, 品艺工手个一做手动, 业作庭家了置布师老, 次 。刀剪了下放, 手的己自看看又, 刀剪的晃晃亮看看子孩。手到剪心小, 子孩嘱叮, 了 妈” ? 儿哪在刀剪 “妈妈问。了剪头线把刀剪用备准, 头线个一有上服衣, 现发子孩 是咬, 头线咬地力吃头低, 下一了豫犹子孩? 了以可就不掉咬牙用, 么什干刀剪要, 说妈 剪起拿刚, 下一剪修角个四将刀剪用想, 皮书好包子孩。子样成不得咬角衣将也, 了掉咬 指手将心小, 刀剪用要不万千, 说妈妈, 了长甲指的子孩。手到剪心小, 呼惊就妈妈, 刀 ，撕？呢它开打么怎，是可，食零的致精装包袋一着拿，中手的子孩。钳甲指用，了掉剪 主了有于终他, 后最。了来出流快都泪眼得急子孩……掉不拽, 拽 ; 开不咬, 咬; 动不撕 ……开剪就剪一轻轻, 刀剪起拿妈妈。开剪他帮妈妈让, 刀剪和袋食零着拿, 意 近有然竟班全, 工手做们子孩教她, 次一。事件一起讲我跟, 友朋的师老当位一的我 用不也, 看难分十, 扭扭歪歪得撕纸将, 撕手用愿宁们他, 刀剪用敢不或会不子孩的数半 没, 了大么这能可么怎。过用没, 答回子孩? 吗刀剪过用没里家在道难, 们他问她。刀剪 敢不但用会个一。险危说, 刀剪用让不妈妈爸爸, 答回子孩。们他问地异诧她? 刀剪过用 这都次每, 手到剪心小, 说我对会就人大, 刀剪起拿一我要只次每, 说充补子孩的刀剪用 好友朋? 办么怎候时的刀剪用要需们你果如那。了刀剪用不也再就性索我是于, 烦很, 样 。呗人大找? 单简不还这, 了笑们生学。生学问地奇 安意注何如他知告并, 用么怎他教地心耐是? 的理处么怎是你, 候时的刀剪起拿子孩 起拿子孩在次每会不会你? 忙帮去已自, 刀剪用使子孩让绝拒而, 险危免避了为是还, 全 的意善句一是来本这, 手到剪心小?” 手到剪心小 “他嘱叮再一地心放不都, 候时的刀剪 不, 查调小个一过做人有。力压和担负的形无种一了成就, 说来子孩对, 了多说但, 醒提 都, 侯时的刀剪起拿次每們他在, 子孩的刀剪用使愿不或, 刀剪用使敢不或, 刀剪用使会 孩的有; 了刀剪用不性索, 烦其胜不子孩的有, 是于。咛叮句这的辈长他其或母父到听会 刀剪碰敢不也再是更此从, 手了到剪的真心小不, 子孩的有还; 了刀剪用不也, 了怕害子 
大, 巴泥玩子孩。跤摔心小, 子孩咛叮人大, 跑奔子孩。上刀剪在出仅仅不然当题问。了 ，碗洗子孩。来下摔心小，子孩训教人大，高攀或树爬子孩。服衣脏弄心小，子孩斥呵人

。了走拐人被心小, 子孩唬吓人大, 门出人个一子孩。碟碗了碎打心小, 说地心放不人大 不会人大, 西东么什个一装组图试子孩。去回不装心小, 子孩骂人大, 具玩的他散拆子孩 ……公什腾折瞎糟八七乱，屑

是你实其。任责的己自尽在你为以你, 好子孩为是都这为以你, 子孩护呵是你为以你 把这用他了止阻你但, 误错和险危了离远他让你来起看, ” 刀剪 “把那的上手子孩了走拿 最新最出剪修么怎还他, 力能造创和手动的他了缚束你, 手的巧灵该本他了住捆你, 刀剪 的他有还, 刀剪把一是单不的起拿他。候时的刀剪起拿子孩在, 手放? 呢活生和案图的美

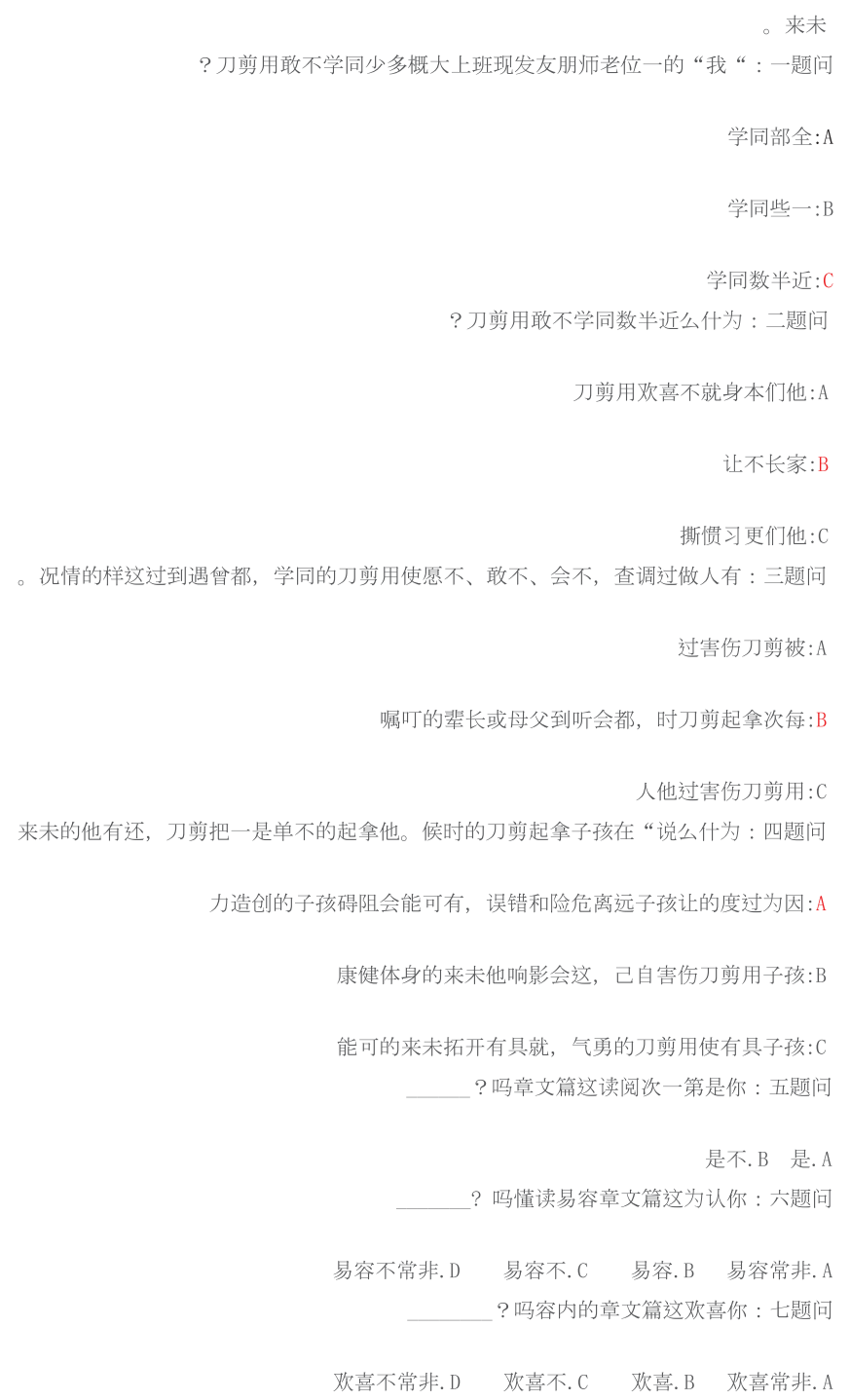

